\title{
Phytochemical Screening of Okra plant from Libya
}

Ahmed Belgasem Ahmed $^{1 *}$, Hamed Alqamoudy ${ }^{1}$, Ameerah Shaeroun ${ }^{1}$, Ahlam Rashed ${ }^{1}$, EL-Mahmoudy ${ }^{1}$, Akram Almabrouk Misbah ${ }^{3}$, Nadea Almunir ${ }^{1}$, Manal M Elshili ${ }^{1}$, FadiaTaufik M $^{2}$, Nouri Kushlaf ${ }^{1}$

${ }^{1}$ Faculty of Science /Zawia University Libya

${ }^{2}$ Faculty of Medicine / Zawia University Libya

${ }^{3}$ Medical Research Center / Zawia City Libya

DOI: $10.36348 /$ SIJCMS.2019.v02i06.002

| Received: 14.09.2019| Accepted: 23.09.2019| Published: 11.10.2019

*Corresponding author: Ahmed Belgasem Ahmed

\section{Abstract}

The interest in medicinal plants in all modern scientific research remains to discover many medicines and drugs to reduce incurable diseases. This study aimed at detecting the effective chemical compounds, flavonoids, tannins, alkaloids. In addition, the possibility of separating some of these compounds by TLC. The results obtained from this study have shown that most of these compounds are found. In addition to the ability of organic mobile phase to separate of these components where the values of $R_{f}$ one to three spots .It indicates the difference in polarity and the composition of these compounds found in Okra under study.

Key words: Medicinal plants, Okra, Drug discovery.

Copyright @ 2019: This is an open-access article distributed under the terms of the Creative Commons Attribution license which permits unrestricted use, distribution, and reproduction in any medium for non-commercial use (NonCommercial, or CC-BY-NC) provided the original author and source are credited.

\section{INTRODUCTION}

Human are consuming vegetables frequently. These plants hold key molecules such as vitamins, antioxidants, phytosterols and fiber. In addition these plants have important medicinal benefits which are increasing rapidly and grabbing human attention. The bioactive compounds from these plants such as Flavonoids, Alkaloids, tannin and carotenoids play an important role in the treatment of many incurable diseases. They are considered as a major source in the discovery of modern medical drugs [1]. Okra (Abelmoschus esculentes) widely grows in most of the countries all around the world especially in the Africa. The maturity period of the okra is said to be between 60-180 days and was known to be a minor crop. It is known to be a solution for various health complications as $85 \%$ of the vegetable is water and the rest comprises of different metabolic products embedded in the mucilaginous substance. It is also practiced as a traditional medication in an array of cultures. The seeds of okra are unique in their structure, where they are rich in proteins, tryptophan, and methionine that make the seeds are carrying all the medicinal benefits [2].

The seeds are also known to be used in the production of oils and more interestingly they can be used as a substitute for non-caffeinated beverages. The seed powder of Okra can be used in water treatment procedures as a substitute to aluminum salt. Okra contributes to be one of the best antioxidants and inhibits the growth of cancer cells. The antioxidant property is due to the oligomeric catechins and derivatives of flavonoids, which are potent antioxidant key factors [3]. Furthermore, scientific evidence shows that okra fresh seeds have the highest amounts of betacarotene [4]. Hence, the objective of this study is to primary phytochemical screening sources.

\section{Preparation of Extracts}

5 grams of each selected dried plant powder were weighed and added to a $50 \mathrm{ml}$ of (methanol, Ethanol, Ethyl acetate and Water) in a conical flask of a $200 \mathrm{ml}$ capacity. The flask was covered and left aside for a 24 hour. The plant mixture was mixed using a magnetic mixer and and filtered then the plant extract was kept in the refrigerator until use.

\section{Preliminary Phytochemical Screening}

Screening of the above selected medicinal plant for various phytochemical constituents were carried out using standard methods [5]. Qualitative phytochemical screening of plant extracts was carried out using the following methods to test only the presence of secondary metabolites. 


\section{Test for Tannins}

$0.008 \mathrm{M}$ Potassium ferricyanide was added to $1 \mathrm{ml}$ of the extract in a test tube, $1 \mathrm{ml}$ of $0.02 \mathrm{M}$ Ferric chloride containing $0.1 \mathrm{~N}$ hydrochloric acid was also added. A blue-black coloration was observed.

\section{Test for Flavonoids}

Crude extract was added to $5 \mathrm{ml}$ of diluted ammonia solution and concentrated $\mathrm{H}_{2} \mathrm{SO}_{4}$. Yellow coloration which disappeared on standing indicates the presence of flavonoids.

\section{Test for Alkaloids}

Crude extract was dissolved with $2 \mathrm{ml}$ of $1 \%$ $\mathrm{HCl}$ and heated gently. Mayers reagents were added to the mixture. Turbidity of the resulting precipitate was taken as confirmation for the presence of alkaloids.

\section{Thin Layer Chromatography (TLC) Analysis}

The Ethanolic, Methanolic, Ethyl acetate and Water Okra extracts were loaded on silica plate (Merck Aluminium sheet-silica gel $60 \mathrm{~F} 254)$. A mixture of H:C:M(1:1:1), P:E:W(1:2:1), M:E:W(1:1:2) and $\mathrm{P}: \mathrm{M}: \mathrm{W}(3: 1: 1)$ were used as the solvent system. The TLC plate was kept in iodine chamber for one minute and under UV light $(254 \mathrm{~nm})$ to visualize bands on chromatogram $[6,7]$.

\section{RESULT AND DISCUSSION}

Medicinal plants are considered as a repository of numerous types of bioactive compounds possessing varied therapeutic properties. Which includes antiinflammatory, antiviral, antitumor, antimalarial, and analgesic effects [8].

The results of plant extract under investigation are shown Table 1. Leaves extract showed positive result for the presence of medicinally active constituents. In the Water extract; tannins, phenolic compounds, flavonoids, alkaloids, were the most common present in the tested plants. While phenolic compounds are absent in methanolic, Ethanolic and Ethyl acetate extract. These finding correlated well with several earlier publications Praveen Garg and Rajesh Garg 2019 [9]. Plants which rich in a wide variety of secondary metabolites, such as terpenoids, alkaloids, tannins, flavonoids appear biological and pharmacological activities and may have potential to be used as chemotherapeutic agents or serve as starting material in the developing of new antibiotics.

Table-1: Preliminary phytochemical screening of Okra extract

\begin{tabular}{|l|l|l|l|l|}
\hline \multirow{2}{*}{ leaves methanolic extract } & phytochemical compounds of Okra \\
\cline { 2 - 5 } & Phenolic compound & Flavonoids & Alkaloids & Tannins \\
\hline Methanolic extract & -ve & + & -ve & + \\
\hline Ethanolic extract & -ve & -ve & +++ & +++ \\
\hline Ethyl acetate extract & -ve & + & & -ve \\
\hline Water extract & +++ & + & +++ & +++ \\
\hline
\end{tabular}

$(+++)$ high (++) medium (+) poor (-) no found

Table-2: Thin Layer Chromatography

\begin{tabular}{|l|l|l|l|l|}
\hline & \multicolumn{4}{|l|}{$\mathbf{R}_{\mathbf{f}}$ values } \\
\hline & Methanolic Extract & Ethanolic & Ethyl acetate & water extracts \\
\hline H:C:M(1:1:1) & $0.25,0.29$ & $0.085,0.148$ & $0.106,0.212,0.97$ & $0.063,0.074,0.106$ \\
\hline P:E:W(1:2:1) & $0.71,0.77,0.82,0.91$ & - & $0.68,0.77$ & 0.77 \\
\hline M:E:W(1:1:2) & $0.028,0.074,0.048$ & $0.029,0.0102,0.42$ & $0.075,0.45,0.54$ & - \\
\hline P:M:W(3:1:1) & $0.45,0.72$ & $0.5,0.67,0.85$ & $0.45,0.82$ & - \\
\hline
\end{tabular}

Thin Layer Chromatography Profiling. Several bands or spots were observed during partitioning of extract components with different mobile phases systems indicating separation of bioactive compounds depending on polarity [10]. The $R F$ values are shown in Table 2 of methanolic, Ethanolic, Ethyl acetate and water extracts.

\section{CONCLUSION}

This research indicates that the tested parts of Okra are containing phenolic and flavonoids compounds. However, further investigation is necessary to separate and characterize the component of each individual extracte. These plants could be added to the long list of promising medicinal plants that offer distinctive source of natural antioxidants that can be used on industrial or medical scales.

\section{REFERENCES}

1. Bhattacharya, R., \& Basu, P. (2018, March). Pollinator Limitation and Crop Production: Experimental Observations on Few Economically Important Vegetable Crops in West Bengal, India. In Proceedings of the Zoological Society. Springer India, 71(1): 88-91.

2. Jarret, R. L., Wang, M. L., \& Levy, I. J. (2011). Seed oil and fatty acid content in okra (Abelmoschus esculentus) and related species. Journal of agricultural and food chemistry, 59(8), 4019-4024. 
3. Kerure, P., \& Pitchaimuthu, M. (2019). Evaluation for heterosis in okra (Abelmoschus esculentus L. Moench). Electronic Journal of Plant Breeding, 10(1), 248-255.

4. Hu, S. M., \& Lai, H. S. (2017). Developing low-fat banana bread by using okra gum as a fat replacer. Journal of Culinary Science \& Technology, 15(1), 36-42.

5. Saha, D., Jain, B., \& Jain, V. K. (2011) Phytochemical evaluation and characterization of hypoglycemic activity of various extracts of Abelmoschus esculentus Linn. Fruit. Int J Pharm Pharm Sci, 3(2), 183-185.

6. Verma, A., Dwivedi, S., \& Singh, N. (2013). Spectral Analysis of Steroidal Saponin Isolated and Purified from Leaves Extract of Asparagus racemosus (Family-Asparagaceae). American Journal of Advanced Drug Delivery, 770-776.

7. Talukdar AD, Choudhury MD, Chakraborty M, Dutta BK. Phytochemical screening and TLC profiling of plant extracts of Cyathea gigantea (Wall. Ex. Hook.) Haltt. and Cyathea brunoniana. Wall. Ex. Hook (Cl. \& Bak.). Assam University Journal of Science and Technology. 2010 May 14;5(1):70-4.

8. Jemal, A., Bray, F., Center, M. M., Ferlay, J., Ward, E., \& Forman, D. (2011). Global cancer statistics. CA: a cancer journal for clinicians, 61(2), 69-90.

9. Abobaker, D. M., Edrah, S. M., \& Altwair, K. Phytochemical Screening of Abelmoschus esculentus From Leptis area at Al-Khums Libya. Development, 17(18), 19.

10. Doreddula, S. K., Bonam, S. R., Gaddam, D. P., Desu, B. S. R., Ramarao, N., \& Pandy, V. (2014). Phytochemical analysis, antioxidant, antistress, and nootropic activities of aqueous and methanolic seed extracts of ladies finger (Abelmoschus esculentus L.) in mice. The Scientific World Journal, 2014. 